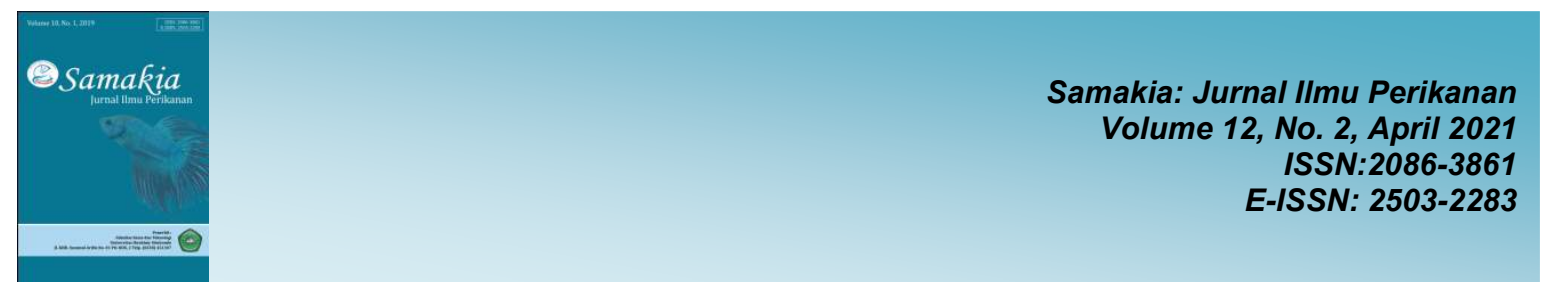

\title{
Pendederan Ikan Bandeng pada Keramba Jaring Apung Sebagai Alternatif Pemanfaatan Waduk Palasari, kabupaten Jembrana, Bali
}

\author{
Nursery of Milkfish in Floating Net Cages as an Alternative Utilization of Palasari Reservoir, Jembrana \\ Regency, Bali
}

Apri I. Supii*, Zeni Widyastuti, I Wayan Budiastawa, dan Toni Setyadarma

Balai Besar Riset Budidaya Laut dan Penyuluhan Perikanan

$\mathrm{Br}$ Gondol, Desa Penyabangan, Kecamatan Gerokgak, Buleleng-Bali

Penulis korespondensi : E-mail : aprisupii@yahoo.co.id

(Diterima November 2020/ Disetujui April 2021)

\begin{abstract}
ABTRACT
The Palasari Dam is a potential public water area and can be developed to produce milkfish in freshwater. The aim of this research is to determine the proper size of the growth and survival of milkfish during nursery activities in floating net cages at the Palasari dam. This study used two groups of tested fish, the first was milkfish seeds from a hatchery in Gondol, Buleleng, Bali with a size of $1.2-1.5 \mathrm{~cm}$ (Group A) and milkfish seeds from a Gresik pond, East Java with a size of 3.5 4. $\mathrm{cm}$ (Group B). Each group is maintained in floating cages with a size of $3 \times 3 \times 3 \mathrm{~m}$. The density for the first group was 5000 individuals / net and the second group was 1000 individuals / net, with each group having three replications. The growth rate of group $A$ was $4.19 \%$ with survival rate of $62.70 \% \pm 5.16$, while in group $B$ the growth rate was $18.13 \%$ with survival rate of $70.65 \% \pm 3.18$. The stocking size of group $B$ milkfish seeds resulted in a higher growth rate and survival rate compared to group A milkfish seeds.
\end{abstract}

Keywords: Milkfish, Floating Net Cages, Palasari Reservoir.

\section{ABSTRAK}

Waduk Palasari merupakan perairan umum yang potensial dan dapat dikembangkan untuk menghasilkan ikan bandeng ukuran konsumsi di perairan tawar.Tujuan dari penelitian ini adalah untuk mengetahui ukuran yang tepat terhadap pertumbuhan dan kelulushidupan ikan bandeng pada keigatan pendederan di keramba jaring apung di Waduk Palasari. Penelitian ini menggunakan dua kelompok hewan uji, yang pertama benih bandeng dari hatchery di Gondol, Buleleng, Bali dengan ukuran 1,2 -1,5 cm (Kelompok A) dan benih bandeng dari tambak Gresik, Jawa Timur dengan ukuran 3,5-4 cm (Kelompok B). Masing-masing kelompok di pelihara pada Keramba Jaring Apung dengan ukuran $3 \times 3 \times 3 \mathrm{~m}$. Kepadatan untuk kelompok A adalah 5000 ekor/ jaring dan kelompok B sebayak 1000 ekor/ jaring, dengan masing-masing kelompok memiliki tiga kali ulangan.Laju pertumbuhan kelompok $A$ sebesar 4,19\% dengan kelulusan hidup $62,70 \%$ $\pm 5,16$, sedangka pada kelompok B laju pertumbuhan sebesar $18,13 \%$ denan kelulusan hidup sebesar $70,65 \% \pm 3,18$. Ukuran tebar benih bandeng kelompok B menghasilkan laju pertumbuhan dan kelulusan hidup yang lebih tinggi dibadingkan dengan benih bandeng kelompok $A$.

Kata Kunci : Bandeng, Keramba Jaring Apung, Waduk Palasari.

\section{PENDAHULUAN}

Ikan bandeng (Chanos chanos) merupakan salah satu komoditas ekonomis penting perikanan budidaya, dan telah ditetapkan oleh Menteri Kelautan dan Perikanan selain sebagai komoditas program industrialisasi, juga sebagai komoditas untuk ketahanan pangan. Ikan bandeng ini sudah lama dapat dibudidayakan, umumnya pada kolam/tambak air payau, keramba jaring apung di laut

To Cite this Paper Supii, A, I., Zeni Widyastut, Z., Budiastawa, I, W., Setyadarma, T., 2021. Pendederan Ikan Bandeng pada Keramba Jaring Apung Sebagai Alternatif Pemanfaatan Waduk Palasari, kabupaten Jembrana, Bali.Samakia: Jurnal IImu Perikanan, 12 (2) : 96-102

Journal Homepage: https://journal.ibrahimy.ac.id/index.php/JSAPI 
(Liao \& Chen 1986; Garcia 1990; Mansyur \& Tonnek 2003), dan di danau-danau dangkal yang berair tawar dengan sistem pen di Philipina dan Taiwan (Liao \& Chen 1986). Budidaya ikan bandeng di perairan tawar, mulai dilakukan di Indonesia pada sekitar tahun 2000 (DKP 2005). Pada saat ini, secara umum kegiatan budidaya Bandeng dapat dibagi menjadi tiga kegiatan yaitu produksi telur, pembenihan dan pembesaran. Selain itu, ada juga jenis kegiatan usaha lainnya yang berbasis Bandeng, seperti pembesaran Bandeng untuk penyediaan umpan penangkapan ikan dan produk makanan olahan berbahan dasar Bandeng.

Ikan bandeng merupakan ikan euryhaline yang dapat beradaptasi pada kisaran salinitas yang luas, dapat hidup di perairan tawar, payau, dan laut (Gordon \& Hong 1986). Ikan bandeng hidup di berbagai tipe habitat, meliputi perairan pantai, muara, kawasan mangrove, laguna, daerah pasang surut (tidal flats), sungai dan daerah berarus (streams).Di alam ikan bandeng banyak dijumpai di daerah pantai dan pulau-pulau di daerah tropik di Indo-Pasifik (Bagarinao 1994).

Kabupaten Jembrana memiliki bendungan/waduk yaitu Waduk Palasari yang merupakan waduk terbesar di Propinsi Bali. Bendungan/Waduk ini mulai dibangun pada April 1986 dan diresmikan pembukaannya pada 23 Juli 1989 oleh Presiden Soeharto. Sebagai penyimpan cadangan air, bendungan Palasari sangat bermanfaat bagi warga sekitar jika musim kemarau tiba terutama untuk pengairan sawah. Memiliki luas lahan sekitar 100 hektar. Bendungan Palasari mampu menampung air hingga mencapai 8 juta meter kubik, sehingga sangat bermanfaat bagi usaha perikanan air tawar. Menurut Jangkara (2000), perairan umum yang banyak dimanfaatkan sebagai tempat budidaya ikan adalah waduk. Salah satu teknologi budidaya yang handal dalam rangka optimasi pemanfaatan perairan waduk adalah budidaya ikan dalam Keramba Jaring Apung (KJA).Kegiatan perikanan di waduk merupakan salah satu alternatif pemanfaatan sumberdaya perairan tersebut. Perkembangan yang pesat budidaya ikan dalam KJA karena memiliki potensi produksi ikan yang dihasilkan, luas perairan yang tersedia, kelestarian sumberdaya, kemudahan melaksanakannya, sudah tersedianya paket teknologi budidaya serta adanya informasi bahwa budidaya ikan dalam KJA memberikan hasil secara ekonomis menguntungkan (Hardjamulia et al. 1991).

Tujuan dari penelitian ini adalah untuk mengetahui ukuran yang tepat terhadap pertumbuhan dan kelulushidupan ikan bandeng pada keigatan pendederan di keramba jaring apung di Waduk Palasari. Hasil penelitian ini diharapkan dapat memberikan informasi dan gambaran kepada masyarakat sekitar Waduk Palasari Desa Ekasari, Kecamatan Melaya, Kabupaten Jembrana, Bali dalam memanfaatkan lahan waduk tersebut.

\section{MATERI DAN METODE}

Penelitian dilakukan di Waduk Palasari, Desa Ekasari, Kecamatan Melaya, Kabupaten Jembrana, Bali (Gambar 1), pada bulan November sampai dengan Desember 2018. Penelitian ini menggunakan dua kelompok hewan uji, yang pertama benih bandeng dari hatchery di Buleleng, Bali dengan ukuran 1,2-1,5 cm (Kelompok $A$ ) dan benih bandeng dari tampak gresik, Jawa Timur dengan ukuran 3,5 $-4 \mathrm{~cm}$ (Kelompok B). Masing-masing kelompok di pelihara pada Keramba Jaring Apung dengan ukuran $3 \times 3 \times 3 \mathrm{~m}$. Kepadatan untuk kelompok pertama adalah 5000 ekor/ jaring dan kelompok kedua sebayak 1000 ekor/ jaring, dengan masing-masing kelompok memiliki tiga kali ulangan.

Pemberian pakan dilakukan sebanyak 3 kali sehari secara adlibitum. Ukuran pakan yang diberikan disesuaikan dengan bukaan mulut benih bandeng. Monitoring pertumbuhan dilakukan seminggu sekali

To Cite this Paper Supii, A, I., Zeni Widyastut, Z., Budiastawa, I, W., Setyadarma, T., 2021. Pendederan Ikan Bandeng pada Keramba Jaring Apung Sebagai Alternatif Pemanfaatan Waduk Palasari, kabupaten Jembrana, Bali.Samakia: Jurnal Ilmu Perikanan, $12(2): 96-102$ 


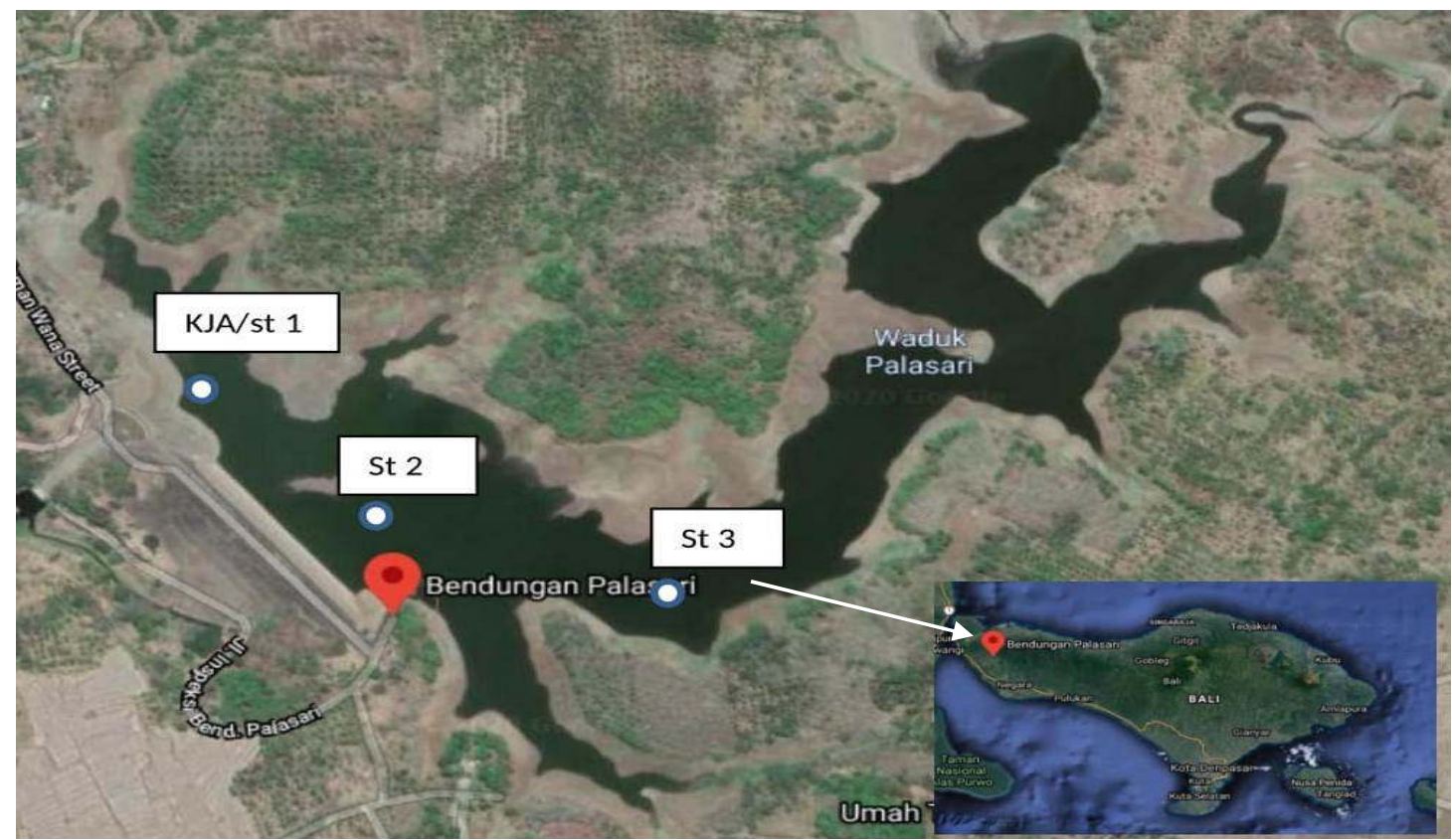

Gambar 1. Peta Waduk/ Bendungan Palasari

Pada uji pertumbuhan dilakukan dengan pengukuran panjang dan pengukuran bobot pada masing-masing perlakuan yang diberikan setiap satu minggu sekali terhitung dari awal ikan masuk ke wadah perlakuan. Setelah didapatkan data setiap minggunya maka dilakukan perhitungan pertumbuhan panjang mutlak, pertumbuhan bobot mutlak, laju pertumbuhan dan kelangsungan hidup.

Laju pertumbuhan spesifik adalah pertumbuhan ikan dalam berat selama waktu pemeliharaan. Rumus yang digunakan pada perhitungan laju pertumbuhan spesifik menurut Effendie (2002).

$g=\frac{\operatorname{InPt}-\operatorname{InPo}}{\mathrm{t}} \times 100 \%$

Keterangan:

$\mathrm{g}=$ Laju pertumbuhan spesifik individu (\%/hari)

$\mathrm{Pt}=$ Bobot rata-rata ikan uji pada akhir pada akhir penelitian (gram)

$\mathrm{Po}=$ Bobot rata-rata ikan uji pada awal penelitian (gram)

$\mathrm{t}=$ Lamanya penelitian (hari)

Pertumbuhan ikan dapat dibedakan menjadi dua yaitu pertumbuhan panjang mutak (PMP) dan pertumbuhan bobot multak (PMB) yang dapat dihitung menggunakan rumus Effendi et al (2006) sebagai berikut:

$\mathrm{L}=\mathrm{L} 2-\mathrm{L} 1$

Keterangan:

$\mathrm{L}=$ Pertumbuhan panjang mutlak individu $(\mathrm{cm})$

L2 = panjang akhir ikan $(\mathrm{cm})$

$\mathrm{L} 1=$ Panjang awal ikan $(\mathrm{cm})$

Adapun rumus yang digunakan untuk mengukur bobot multak dapat dihitung menggunakan rumus Dewantoro (2001), sebagai berikut:

$\mathrm{W}=\mathrm{Wt}-\mathrm{W} 0$

Keterangan:

$\mathrm{W}=$ Pertumbuhan bobot mutlak individu (gram)

$\mathrm{Wt}=$ Bobot akhir ikan (gram)

WO= Bobot awal ikan (gram)

To Cite this Paper Supii, A, I., Zeni Widyastut, Z., Budiastawa, I, W., Setyadarma, T., 2021. Pendederan Ikan Bandeng pada Keramba Jaring Apung Sebagai Alternatif Pemanfaatan Waduk Palasari, kabupaten Jembrana, Bali.Samakia: Jurnal IImu Perikanan, 12 (2) : 96-102

Journal Homepage: https://journal.ibrahimy.ac.id/index.php/JSAPI 
Kelangsungan hidup merupakan sejumlah organisme yang hidup pada akhir pemeliharaan yang dinyatakan dalam persentase (Damayanti et al., 2018). Menurut Effendie (2002), pengujian yang dilakukan pada parameter ukur kelangsungan hidup (survival rate) yang diamati dengan menghitung jumlah ikan pada akhir penelitian dan dihitung berdasarkan rumus yaitu:

$\mathrm{Sr}=\frac{\mathrm{Nt}}{\mathrm{No}} \times 100 \%$

Keterangan:

$\mathrm{Sr}=$ Tingkat kelangsungan hidup ikan uji $(\%)$

$\mathrm{Nt}=$ Jumlah ikan uji yang hidup pada akhir penelitian (ekor)

No $=$ Jumlah ikan uji yang hidup pada awal penelitian (ekor)

Pengambilan sampel fitoplanktondilakukan dengan cara menarik (hauling) plankton net dengan mesh size $28 \mu \mathrm{m}$ secara vertikal dari kedalaman $5 \mathrm{~m}$ sampai permukaan perairan. Contoh air dan fitoplankton yang diperoleh, kemudian dimasukkan ke dalam botol pendinginan, sedangkan untuk fitoplankton berupa pengawetan dengan larutan Lugol $1 \%$ untuk keperluan analisis di laboratorium. Sedangkan untuk pengukuran parameter kualitas air meliputi suhu, oksigen terlarut, nitrat, dan amoniak.

\section{HASIL DAN PEMBAHASAN}

Panjang total awal benih yang berasal dari Gondol $(A)$ adalah $1,34 \pm 0,20 \mathrm{~cm}$. Selama empat minggu pemeliharan terdapat peningkatan pertumbuhan. Ini terlihat bahwa pada minggu ke empat pertambahan panjang menjadi $5,78 \pm 0,45 \mathrm{~cm}$. Hasil pengamatan pertumbuhan terlihat mencolok pada minggu ke tiga. Hasil perhitungan laju pertumbuhan pada kelompok A adalah 4,19\%. Laju pertumbuhan berat menunjukan pola yang linier, dimana pada setiap minggunya terjadi pertumbuhan yang relatif sama. Hasil pengamatan pada minggu ketujuh didapat berat benih

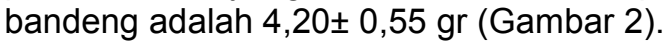

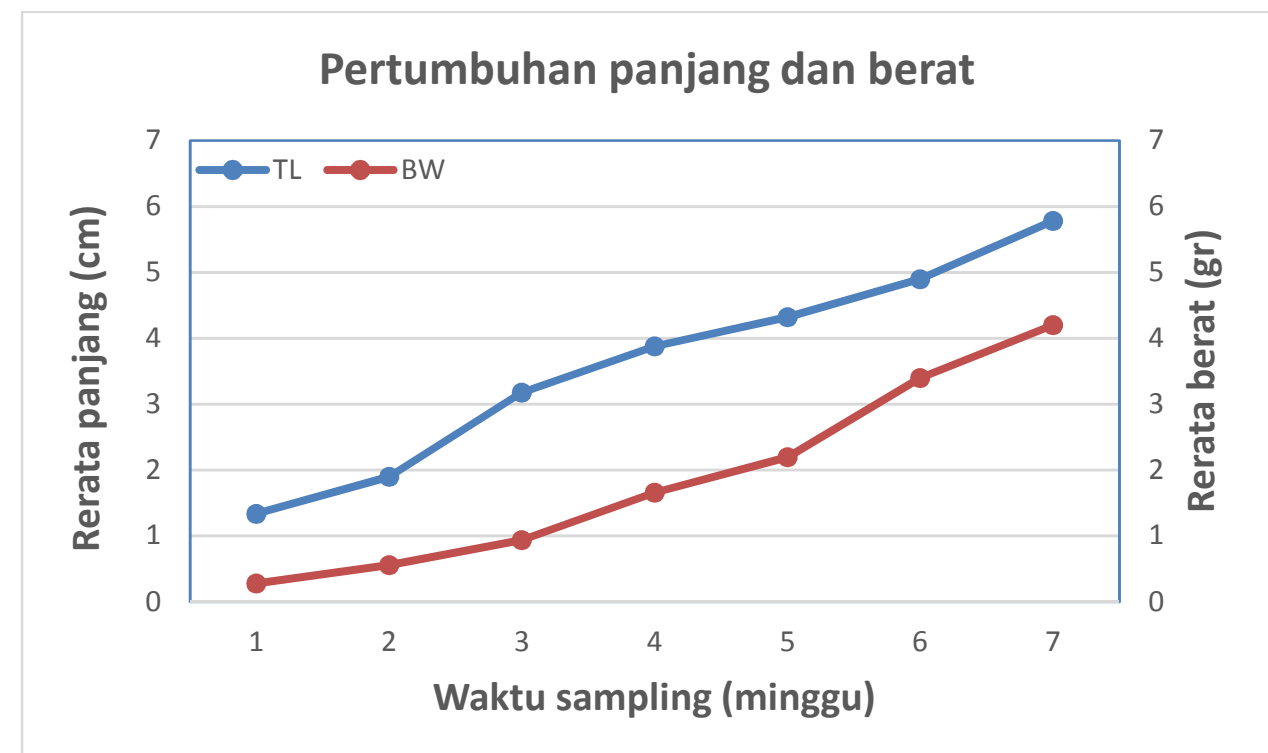

Gambar 2. Grafik Pertumbuhan panjang dan berat benih bandeng kelompok A

Hasil pengamatan pertumbuhan benih dari gresik menunjuukan pertumbuhan yang linier. Dimana pada awal pemeliharaan panjang total adalah $3,76 \pm 0,52 \mathrm{~cm}$ dengan berat $2,82 \pm 0,32 \mathrm{gr}$, menjadi peningkatan pada minggu ketujuh dengan panjang $9,20 \pm 0,94 \mathrm{~cm}$ dengan berat $18,2 \pm 1,68 \mathrm{gr}$ (Gambar 3).Laju pertumbuhan untuk kelompok B adalah 18,13 \%. Laju pertumbuhan adalah kecepatan pertumbuhan ikan perhari. Pengaruh laju pertumbuhan ikan bandeng karena padat penebaran yang berbeda. Hal ini dikarenakan ikan bandeng mempunyai sifat menggerombol dan hidup di kolom air sehingga mengalami persaingan dalam mendapatkan makanan akibat padat

To Cite this Paper Supii, A, I., Zeni Widyastut, Z., Budiastawa, I, W., Setyadarma, T., 2021. Pendederan Ikan Bandeng pada Keramba Jaring Apung Sebagai Alternatif Pemanfaatan Waduk Palasari, kabupaten Jembrana, Bali.Samakia: Jurnal IImu Perikanan, $12(2): 96-102$

Journal Homepage: https://journal.ibrahimy.ac.id/index.php/JSAPI 
penebaran yang tinggi (Sulardioo et. al, 2013). Semakin besar kepadatan ikan yang kita berikan, akan semakin kecil laju pertumbuhan per individu. Dengan kepadatan rendah ikan mempunyai kemampuan memanfaatkan makanan dengan baik dibandingkan dengan kepadatanyang cukup tinggi, karena makanan merupakan faktor luar yang mempunyai peranan di dalam pertumbuhan (Syahid et al, 2006).

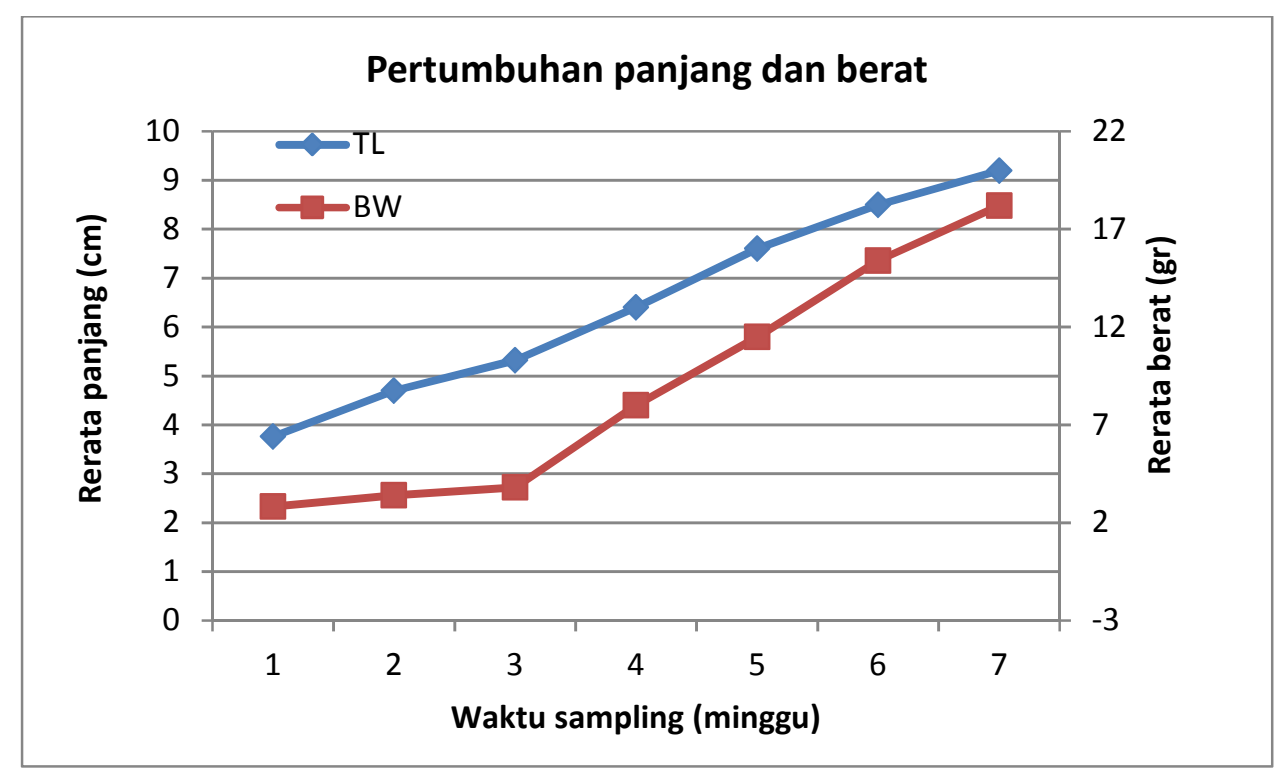

Gambar 3. Grafik Pertumbuhan panjang dan berat benih bandeng kelompok B

Nilai kelulushidupan bandeng tertinggi didapatkan pada penebaran benih bandengkelompok Blebih besar yaitu70,65 \% $\pm 3,18$, sedangkan pada penebaran benih bandeng kelompok $\mathrm{A}$ hanya sebesar62,70\% $\pm 5,16 \mathrm{Hal}$ ini diduga pada penebaran benih bandeng asal Gresik (A) memiliki ukuran benih yang lebih besar, sehingga ikan bandeng telah mampu beradaptasi dengan lingkungan waduk. Sedangkan pada penebaran benih bandeng asal Gondol (B) memiliki kelulusan hidup yang lebih rendah, diduga karena kepadatan yang terlalu tinggi yang menyebabkan ikan menjadistres.Menurut Djatikusumo (1977), faktor kepadatan akan mempengaruhi kelangsungan hidup dari populasi..

Hasil analisa plankton pada perairan bendungan Palasari di dapat beberapa jenis phytoplankton dan zooplankton (Tabel 1). Sebaran plankton pada tepi waduk dan tengah waduk relatif sama. Diman jenis Nitzchia acicularis lebih mendominasi untuk golongan phytoplankton.

Tabel 1. Jenis plankton di perairan Bendungan Palasari

\begin{tabular}{|c|c|c|}
\hline Titik sampel & Jenis plankton & Spesies \\
\hline Tengah waduk & Zooplankton & $\begin{array}{l}\text { Naupli Cyclops } \\
\text { Diacyclops thomasi } \\
\text { Brachionus falcatus } \\
\text { Brachionus mirus } \\
\text { Brachionus plicatilis } \\
\text { Keratella valga var. } \\
\text { Tropica-asymmetrica }\end{array}$ \\
\hline & Phytoplankton & $\begin{array}{l}\text { Nitzschia acicularis } \\
\text { Naupli Cyclops }\end{array}$ \\
\hline Tepi waduk & Phytoplankton & $\begin{array}{l}\text { Diacyclops thomasi } \\
\text { Brachionus falcatus } \\
\text { Brachionus mirus } \\
\text { Brachionus plicatilis } \\
\text { Nitzschia acicularis } \\
\text { Nitzschia palea }\end{array}$ \\
\hline
\end{tabular}

To Cite this Paper Supii, A, I., Zeni Widyastut, Z., Budiastawa, I, W., Setyadarma, T., 2021. Pendederan Ikan Bandeng pada Keramba Jaring Apung Sebagai Alternatif Pemanfaatan Waduk Palasari, kabupaten Jembrana, Bali.Samakia: Jurnal IImu Perikanan, $12(2): 96-102$ 
Lingulodinium polyedrum

Gonyaulax polyedra

Asterionella glacialis

Selain pakan pellet komersial yang diberikan, kecenderungan benih bandeng juga memakan plankton yang berada pada perairan bendungan. Ini memungkinkan untuk bandeng yang telah dilepas akan mempunyai peluang hidup yang tinggi. Menurut Bagarinao (1994) bahwa Jenis makanan ikan bandeng bervariasi bergantung kepada stadia hidup dan habitatnya (Bagarinao 1994). Jenis makanan ikan bandeng bervariasi tergantung dari stadia hidup dan habitatnya, dimana ikan bandeng dewasa makanan utamanya terdiri dari organisme benthik dan planktonik yang terdiri dari gastropoda, lamellibranchia, foraminifera, alga filamen, diatoms, copepod,nematoda, dan detritus (Garcia.,1990),.Djumanto et al, (2017) menatakan bahwa makanan ikan bandeng di Waduk Sermo mengalami pergeseran. Pada ukuran kecil dengan panjang total $<14 \mathrm{~cm}$ atau umur muda makanan utama adalah fitoplankton yang didominasi oleh Nitzchia sp., sedangkan setelah tumbuh besar atau ukuran $>15 \mathrm{~cm}$ maka zooplankton menjadi makanan pelengkap yang didominasi oleh Cyclop sp. Pemilihan makanan ikan bandeng terhadap jenis plankton tertentu dipengaruhi oleh kebutuhan dan ketersediaannya di perairan. Pada umur muda kebutuhan energi untuk pertumbuhan sangat tinggi, sehingga konsumsi Nitzchia sp. Sangat tinggi bahkan mencapai 1,5 kali konsentrasinya di perairan (Djumanto et al, 2017).

Hasil pengaamatan kualitas air selama kegiatan didapat bahwa kondisi perairan di waduk cukup baik untuk kehidupan bandeng. Hasil pengujian kualitas air ini disajikan pada tabel dibanwah ini.

Tabel 3. Kualitas air di perairan Bendungan Palasari

\begin{tabular}{ccccc}
\hline No & Parameter & Satuan & Tepi Bendungan & Tengah Bendungan \\
\hline 1 & Suhu & ${ }^{\circ} \mathrm{C}$ & $27-29$ & $27-29$ \\
2 & DO & $\mathrm{mg} / \mathrm{L}$ & $6,5-7,5$ & $6,3-7$ \\
3 & Ammoniak & $\mathrm{mg} / \mathrm{L}$ & $0,0145-0,0355$ & $0,0135-0,0436$ \\
4 & Nitrit & $\mathrm{mg} / \mathrm{L}$ & $<0,0015$ & $<0,0015$ \\
\hline
\end{tabular}

\section{KESIMPULAN}

Laju pertumbuhan ukuran benih tebar $1,2-1,5 \mathrm{~cm}$ sebesar 4,19\% dengan kelulusan hidup 62,70 $\% \pm 5,16$, sedangkan pada ukuran benih tebar $3,5-4 \mathrm{~cm}$ laju pertumbuhan sebesar $18,13 \%$ denan kelulusan hidup sebesar $70,65 \% \pm 3,18$. Ukuran tebar benih bandeng $3,5-4 \mathrm{~cm}$ menghasilkan laju pertumbuhan dan sintasan yang lebih tinggi di badingkan dengan benih bandeng ukuran $1,2-1,5 \mathrm{~cm}$.

\section{DAFTAR PUSTAKA}

Bagarinao T. 1994. Systematics, distribution, ge-netics and life history of milkfish, Chanos chanos. Environmental Biology of Fishes, 39(1): 23-41

Djatikusumo, E. W. 1977. Dinamika Populasi.AUP. Jakarta.148 hlm

Djumanto, Bayu Eko Pranoto, Vinta Seta Diani, Eko Setyobudi. 2017. Makanan dan pertumbuhan ikan bandeng, Chanos chanos (Forsskål, 1775) tebaran di Waduk Sermo, Kulon Progo. Jurnal Iktiologi Indonesia, 17(1): 83-100

Garcia LMB. 1990. Fisheries Biology of Milkfish (Chanos chanos Forskal) in Proceedings of the Regional Workshop on Milkfish Culture Development in the South Pacifictarawa, Kiribati, 21-25 November 1988. South Pacific Aquaculture Development Project, Food and Agriculture Organization of the United Nations.

Gordon MS, Hong LQ. 1986. Biology of Chanos chanos. Di dalam: Lee CS, Gordon MS, Watanabe WO. editor. Aquaculture of Milkfish (Chanos chanos): State of the Art. The Oceanic Institute Makapuu Point Waimanalo, Hawai. hlm 1-33.

Jangkara, J. 2000. Pembesaran Ikan Air Tawar Di Berbagai Lingkungan Pemeliharaan. Jakarta: Penebar Swadaya.

To Cite this Paper Supii, A, I., Zeni Widyastut, Z., Budiastawa, I, W., Setyadarma, T., 2021. Pendederan Ikan Bandeng pada Keramba Jaring Apung Sebagai Alternatif Pemanfaatan Waduk Palasari, kabupaten Jembrana, Bali.Samakia: Jurnal IImu Perikanan, 12 (2) : 96-102 
Liao IC, Chen TI. 1986. Milkfish Culture Methods in Southeast Asia. Di dalam: Lee CS, Gordon MS, Watanabe WO. editor. Aquaculture of Milkfish (Chanos chanos): State of the Art. The Oceanic Institute Makapuu Point Waimanalo, Hawai. hlm 209-238.

Mansyur A, Tonnek. 2003. Prospek Budi Daya Bandeng dalam Karamba Jaring Apung Laut dan Muara Sungai. Jurnal Litbang Pertanian, 22(3) : 79-85.

Nurnaningsih. 2004. Pemanfaatan Makanan oleh Ikan-ikan Dominan di Perairan Waduk Ir. H. Djuanda. [tesis] Bogor: Sekolah Pascasarjana Institut Pertanian Bogor.

Sulardiono, B., Supriharyonodan Rina Susanti.,2013. Kajian Tentang Laju Pertumbuhan Ikan Bandeng (Chanos chanosforskall) Pada Tambak Sistem Silvofishery Dan Non SilvofisheryDi Desa Pesantren Kecamatan Ulujami Kabupaten Pemalang. Journal Of Management Of Aquatic Resources. Volume 2,Nomor 2,Tahun 2013, Halaman 81-86

Syahid M, A Subhan, dan R Armando. 2006. Budidaya Bandeng Organik Secara Polikultur. Jakarta: Penebar Swadaya.

To Cite this Paper Supii, A, I., Zeni Widyastut, Z., Budiastawa, I, W., Setyadarma, T., 2021. Pendederan Ikan Bandeng pada Keramba Jaring Apung Sebagai Alternatif Pemanfaatan Waduk Palasari, kabupaten Jembrana, Bali.Samakia: Jurnal IImu Perikanan, 12 (2) : 96-102

Journal Homepage: https://journal.ibrahimy.ac.id/index.php/JSAPI 